\title{
Left Ventricular Reconstruction Surgery in Candidates for Heart Transplantation
}

Carlos Alberto Méndez Contreras' ${ }^{1}, \mathrm{MD}$, PhD; Pedro Xavier Orellana ${ }^{1}, \mathrm{MD}$; Antonio Flávio Sanchez de Almeida ${ }^{1}$, MD; Marco Aurélio Finger ${ }^{1}$, MD; João Manoel Rossi Neto ${ }^{1}$, MD; Paulo Chaccur ${ }^{1}$, MD

DOI: $10.21470 / 1678-9741-2018-0087$

\begin{abstract}
Objective: To report our center's experience in the surgical treatment of ventricular reconstruction, an effective and efficient technique that allows patients with end-stage heart failure of ischemic etiology to have clinical improvement and increased survival.

Methods: Observational, clinical-surgical, sequential, retrospective study. Patients with ischemic cardiomyopathy and left ventricular aneurysm were attended at the Heart Failure, Ventricular Dysfunction and Cardiac Transplant outpatient clinic of the Dante Pazzanese Cardiology Institute, from January 2010 to December 2016. Data from 34 patients were collected, including systemic arterial hypertension, ejection fraction, New York Heart Association (NYHA) functional classification (FC), European System for Cardiac Operative Risk Evaluation (EuroSCORE) II value, Society of Thoracic Surgeons (STS) score, ventricular reconstruction technique, and survival.
\end{abstract}

Results: Overall mortality of $14.7 \%$, with hospital admission being $8.82 \%$ and late death being $5.88 \%$. Total survival rate at five years of $85.3 \%$. In the preoperative phase, NYHA FC was Class I in five patients, II in 18, III in eight, and IV in three vs. NYHA FC Class I in 17 patients, II in eight, III in six, and IV in three, in the postoperative period. EuroSCORE II mean value was $6.29, P \leq 0.01$; hazard ratio (HR) 1.16 (95\% confidence interval [Cl] 1.02-1.31). STS mortality/morbidity score mean value was $18.14, P \leq 0.004 ; H R 1.19$ (95\% Cl 1.05-1.33). Surgical techniques showed no difference in survival among Dor $81 \%$ vs. Jatene $91.7 \%$.

Conclusion: Surgical treatment of left ventricular reconstruction in candidates for heart transplantation is effective, efficient, and safe, providing adequate survival.

Keywords: Cardiac Surgical Procedures. Stroke Volume. Heart Aneurysm. Heart Transplantation. Survival Rate.

\begin{tabular}{|c|c|c|c|}
\hline \multicolumn{2}{|c|}{ Abbreviations, acronyms \& symbols } & \multirow[b]{2}{*}{ HF } & \multirow[b]{2}{*}{$=$ Heart failure } \\
\hline ABTO & $=$ Brazilian Organ Transplantation Association & & \\
\hline AMI & $=$ Acute myocardial infarction & HR & $=$ Hazard ratio \\
\hline CAD & $=$ Coronary artery disease & HTx & $=$ Heart transplantation \\
\hline CCS & = Canadian Cardiovascular Society & ISHLT & $=$ International Society of Heart and Lung \\
\hline CEP & $=$ Ethics and Research Commission & & Transplantation \\
\hline $\mathrm{CHF}$ & $=$ Congestive heart failure & LVESVI & $=$ Left ventricular end-systolic volume index \\
\hline $\mathrm{Cl}$ & $=$ Confidence interval & MR & = Myocardial revascularization \\
\hline DATASUS & $\begin{aligned}= & \text { Information Technology Department of the } \\
& \text { Brazilian Public Health Care System }\end{aligned}$ & $\begin{array}{l}\text { NYHA } \\
\text { SAH }\end{array}$ & $\begin{array}{l}=\text { New York Heart Association } \\
=\text { Systemic arterial hypertension }\end{array}$ \\
\hline EF & $=$ Ejection fraction & SBCCV & = Brazilian Cardiovascular Surgery Society \\
\hline ESC/EACTS & $\begin{aligned}= & \text { European Society of Cardiology/European } \\
& \text { Association for Cardiothoracic Surgery }\end{aligned}$ & $\begin{array}{l}\text { SPSS } \\
\text { STICH }\end{array}$ & $\begin{array}{l}=\text { Statistical Package for the Social Sciences } \\
=\text { Surgical Treatment for Ischemic Heart Failure }\end{array}$ \\
\hline EuroSCORE & $\begin{aligned}= & \text { European System for Cardiac Operative Risk } \\
& \text { Evaluation }\end{aligned}$ & $\begin{array}{l}\text { STS } \\
\text { SVR }\end{array}$ & $\begin{array}{l}=\text { Society of Thoracic Surgeons } \\
=\text { Surgical ventricular reconstruction }\end{array}$ \\
\hline FC & $=$ Functional classification & & \\
\hline
\end{tabular}

'Division of Cardiovascular Surgery of Instituto Dante Pazzanese de Cardiologia, São Paulo, SP, Brazil.

This study was carried out at Instituto Dante Pazzanese de Cardiologia, São Paulo, SP, Brazil.
Correspondence Address:

Carlos Alberto Méndez Contreras

(iD) https://orcid.org/0000-0002-4980-3600

Instituto Dante Pazzanese de Cardiologia

Av. Dr. Dante Pazzanese, 500 - Vila Mariana - São Paulo, SP, Brazil.

Zip Code: 04012-909

E-mail: carlosmendez701@yahoo.com 


\section{INTRODUCTION}

Coronary artery disease (CAD), whose clinical manifestations are angina pectoris, acute myocardial infarction (AMI), sudden death, or ischemic cardiomyopathy, is the leading cause of death in Brazil, according to the Information Technology Department of the Brazilian Public Health Care System (DATASUS) ${ }^{[1]}$.

Ischemic cardiomyopathy is responsible for approximately $60 \%$ of the etiology of patients with heart failure $(\mathrm{HF})^{[2]}$, who may present variable degree of ventricular dysfunction.

When we evaluate the possibilities of treatment of these patients, they range from the prevention of reversible factors, such as CAD and hyperthyroidism, to clinical treatment that includes pharmacological and non-pharmacological strategies, cardiac resynchronization therapy and cardiac defibrillator implantation, and in the final stage of HF, the use of circulatory assistance devices as a bridge to heart transplantation ( $\mathrm{HTx}$ ) or as target therapy ${ }^{[3]}$, all of these when optimized can preserve the quality of life and survival of these patients.

Other patients benefit from conventional surgical treatment aimed at myocardial revascularization (MR), isolated and/or concomitant with the treatment of dilation of the left ventricular cavity, secondary to the formation of areas of akinesia or aneurysm ${ }^{[4]}$, as well as to the treatment of mitral regurgitation, resulting from ventricular remodeling due to chronic ischemia.

The surgical ventricular reconstruction (SVR) is a procedure used to treat advanced HF caused by systolic dysfunction and ventricular dilatation after AMI. It aims to reduce the volume and restore the ventricular shape of the heart ${ }^{[3]}$.

SVR can be performed with different techniques; the indication and use of each one is based on the degree of deformity that the ventricular anatomy presents, as described by DiDonato ${ }^{[4]}$. Among the techniques described, we can cite the classic linear suture described in 1958 by Cooley ${ }^{[5]}$, the geometric reconstruction techniques described by Jaten $e^{[6]}$, the Dor's technique ${ }^{[]]}$, performed by reconstruction with the insertion of a patch in the left ventricle, and other similar techniques described in 1989 by Cooley ${ }^{[8]}$ and/or in 1994 by Michelborough ${ }^{[9]}$, all with positive results in both evolution and survival rates ${ }^{[6-8,10]}$, as well as recent, multicenter studies, such as the RESTORE group ${ }^{[11]}$ and the Surgical Treatment for Ischemic Heart Failure (STICH) trial[12-14].

When the possibilities of conventional clinical and surgical treatment are exhausted, and in view of the perpetuation of the $\mathrm{HF}$, the possibility of treatment with transplantation is opened. This is considered the gold standard therapy for patients in terminal HF, however, there is a disproportion between donor supply and recipient demand. Data from the Brazilian Organ Transplantation Association (ABTO) ${ }^{[5]}$ for the year 2016 showed that $357 \mathrm{HTx}$ were performed in Brazil, but the estimated annual need for HTx was 1636.

\section{Objective}

To describe the outcome of left ventricular reconstruction surgery in candidates for HTX.

\section{METHODS}

\section{Type of Study}

An observational, clinical-surgical, sequential, retrospective study, with pre and postoperative data collection from patients' medical records.

\section{Population}

The studied population consisted of patients with ischemic cardiomyopathy and left ventricular aneurysm, who were followed up at the Heart Failure, Ventricular Dysfunction and Cardiac Transplant outpatient clinic of the Dante Pazzanese Institute of Cardiology from January 2010 to December 2016.

Thirty-four subjects who had been contraindicated to conventional surgical treatment were evaluated by the Cardiac Transplantation group, who, at a multiprofessional meeting, indicated the treatment of SVR, with or without MR and mitral valve intervention.

\section{Surgical Procedure}

All patients were conventionally prepared for cardiac surgery. Median transsternal thoracotomy was performed, extracorporeal circulation was established, systemic hypothermia was in moderate degree, with intermittent anoxic arrest as myocardial protection method.

The surgical treatment of ventricular reconstruction was performed through:

- Geometric reconstruction technique described by Jatene ${ }^{[6]}$, in which circular reconstruction of the left ventricle wall and internal plication of the left ventricle akinetic septum are performed. A patch $(<10 \%)$ can be used and MR may not be performed (20\%).

- Endoaneurysmorrhaphy technique described by Dor ${ }^{[7]}$, in which a patch is inserted inside the left ventricle on the contractile muscle, excluding all akinetic areas and reconstructing the ventricular cavity as it was before AMl, in addition to MR of all diseased coronary arteries.

Concomitantly and complementing the treatment of SVR, patients were or were not submitted to MR and valvar mitral intervention.

\section{Statistical Analysis}

Data were evaluated by the Statistical Package for the Social Sciences (SPSS) software, version 19. The categorical variables were presented in percentage. General survival and according surgical technique were determined by the Kaplan-Meier curve and a difference test between the log-rank curves was performed. For analysis of the quantitative variables, a univariate Cox regression model was applied. For functional classification (FC) analysis, a McNemar test was used to evaluate the improvement or worsening of it. Significance value of $\mathrm{P} \leq 0.05$ was established.

\section{Ethics and Consent Form}

This study was approved by the Ethics and Research Commission (CEP) of the Dante Pazzanese Institute of Cardiology 
with CAAE 65671917.1.0000.5462 and protocol number in CEP 4738.

\section{RESULTS}

Table 1 shows the baseline characteristics of the 34 patients who composed the study.

\section{Types of Ventricular Reconstruction}

The Jatene's technique was used in 12 patients (35.29\%). All of them were revascularized (100\%) and in two (16.6\%) patients there was mitral valve intervention, a plasty repair and a valve replacement

Dor's technique was used in 21 patients (61.76\%), 17 (80.95\%) were revascularized, eight (38.09\%) underwent mitral plasty repair, and in three (14.28\%) patients only ventricular reconstruction was performed.

When analyzing the Kaplan-Meier survival curve according to the surgical technique employed (Figure 1), no significant difference was observed, $P \geq 0.5$.

\section{Incidence of Intra-aortic Balloon Implantation}

The intra-aortic balloon in the immediate postoperative period was used in one (2.94\%) patient, who underwent Dor's technique exclusively.

\section{Mortality}

There were five deaths in the total number of studied patients (14.7\%). Three of these occurred in the hospital phase (8.82\%), two of which were due to cardiac causes (5.88\%) (cardiogenic shock) and one due to sepsis (2.94\%). Two deaths occurred late (5.88\%).
When evaluating the European System for Cardiac Operative Risk Evaluation (EuroSCORE) II of the patients, we observed that the mean value was 6.29, with a predictor of mortality with significance, $P \leq 0.01$. The hazard ratio (HR) was 1.16 , with a $95 \%$ confidence interval (Cl) between 1.02 and 1.31.

Regarding the Society of Thoracic Surgeons (STS) score, no significance was observed for mortality alone, mean value of

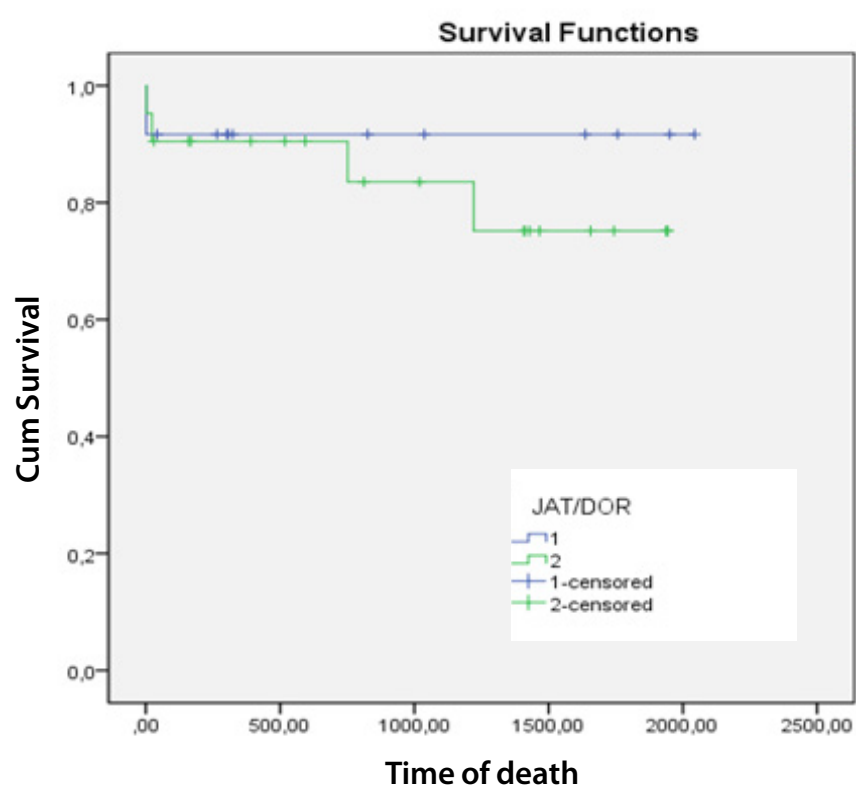

Fig. 1 - Survival of patients according to type of ventricular reconstruction. $1=$ Jatene; $2=$ Dor. Kaplan-Meier survival curve

Table 1. Patients' preoperative characteristics.

\begin{tabular}{l|c|c}
\hline Variables & All (n= 34) & $\boldsymbol{P}$ \\
\hline Age (years) & $55.94 \pm 10.26$ & 0.16 \\
\hline Male sex (\%) & $24(70.6)$ & 0.06 \\
\hline SAH (\%) & $28(82.4)$ & 0.9 \\
\hline Diabetes mellitus type II (\%) & $12(35.3)$ & 0.4 \\
\hline Dyslipidemia (\%) & $25(73.5)$ & 0.5 \\
\hline CHF (\%) & $33(97.1)$ & 0.5 \\
\hline CCS (\%) & $27(79.4)$ & 0.01 \\
\hline EuroSCORE II (mean) & 6.28 & 0.1 \\
\hline STS mortality (mean) & 2.14 & 0.01 \\
\hline STS mortality/morbidity (mean) & 18.14 & 0.8 \\
\hline Ejection fraction (mean) & 31.38 & \\
\hline
\end{tabular}

Data expressed as mean \pm standard deviation or number (\%).

CCS=Canadian Cardiovascular Society's grading system for stable angina; CHF=congestive heart failure; EuroSCORE II=European

System for Cardiac Operative Risk Evaluation; SAH=systemic arterial hypertension; STS=Society of Thoracic Surgeons' 


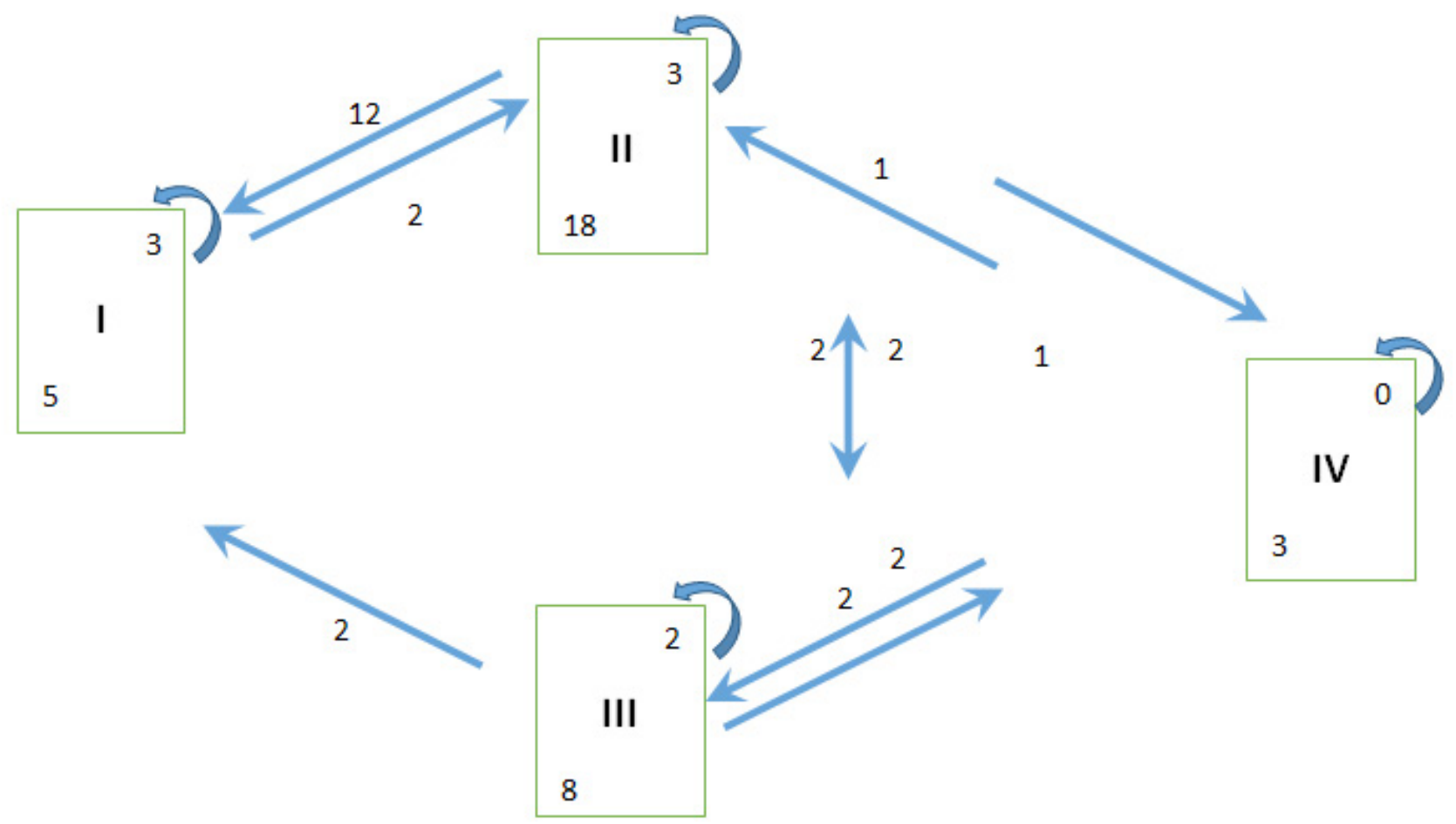

Fig 2 - Evolution of the pre and post-operative functional classification.

2.14 and $P \geq 0.11$. However, the STS mortality/morbidity score had an average value of $18.14, P \leq 0.004$; HR of 1.19 and $95 \% \mathrm{Cl}$ between 1.05 and 1.33 .

\section{Pre- and Postoperative Functional Classification}

The New York Heart Association (NYHA) FC in the preoperative phase was Class I in five patients, Class II in 18 patients, Class III in eight patients, and Class IV in three patients. In the postoperative period, there were 17 patients in Class I, eight patients in Class II, six patients in Class III, and three patients in Class IV. There was change of FC after surgical procedure.

After analyzing the evolution of the FC (Figure 2) in the postoperative period, we observed that the main improvement was from patients in FC II to FC I (66.7\%) and patients in FC III to FC I (25\%). When the McNemar test was applied in the FC analysis, there was an improvement ratio on the same score with odds ratio of 2.71, however with no significance, $P \geq 0.1$.

\section{Ejection Fraction}

The preoperative left ventricular ejection fraction (EF) affected 18 patients between 21 and 30\% and 13 patients between 31 and $50 \%$. In the postoperative period, there were 10 patients with EF between 21 and 30\%, 13 with EF between 31 and 50\%, and one with $\mathrm{EF}>50 \%$. There was a change in postoperative EF values with improvement in those patients who had postoperative data $(n=24)$, although with no significance, $P \geq 0.2$.

\section{Postoperative Complications}

When excluding the five patients who died in the hospital and late phases, 29 patients remain, of which 24 are in the control of the coronary insufficiency by the outpatient clinic, with seven having HF, 14 being asymptomatic, one presenting complication of peripheral vascular disease, one having a stroke, and one with cardiac arrhythmia. Five patients with HF are followed by the cardiac transplantation outpatient clinic, one of them in priority for HTx.

\section{Follow-up}

General survival was $85.3 \%$, with an average follow-up of two years and eight months (one month - five years) (Figure 3). There is a general survival rate of patients up to 2,000 days after procedure.

\section{DISCUSSION}

HF has a high mortality rate in developed countries and it is reported in $25-45 \%$ of cases in one year ${ }^{[16]}$. However, in patients with $\mathrm{HF}$ with a reduced $\mathrm{EF}(<50 \%)$, there is a mortality rate of 32 $68 \%$ in five years ${ }^{[16]}$.

The surgical ventricular reconstruction (SVR) was described as an effective and efficient technique, regardless of the technique employed ${ }^{[17,18]}$, allowing patients to have clinical improvement and increased survival, as described by Cooley ${ }^{[5]}$, Jatene ${ }^{[6]}$, 


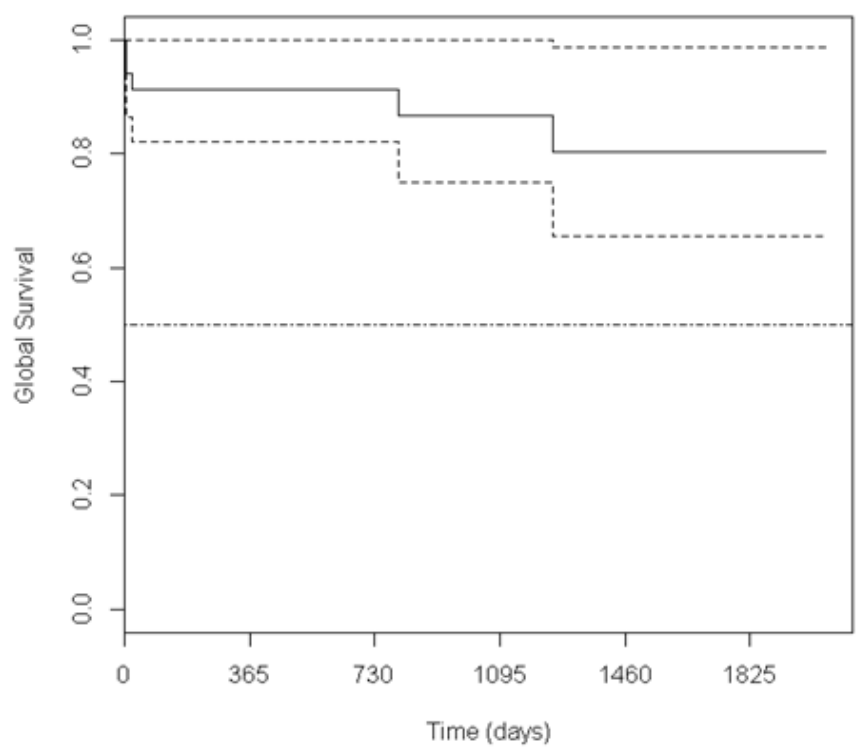

Fig 3 - General survival.

Dor $^{[7]}$, Cooley $^{[8]}$, Michelborough $^{[9]}$, Dinkhuysen ${ }^{[10]}, \mathrm{D}^{\prime}$ Mello ${ }^{[19]}$, and Tekümit ${ }^{[20]}$. Despite the results described, the search for more scientifically consistent information led to multicenter studies, such as that developed by the RESTORE group ${ }^{[11]}$, which achieved a five-year survival rate of $68.6 \%$, with improvement of the preoperative FC of $67 \%$ in class III-IV and $85 \%$ in postoperative functional class I-II. Concomitantly, other authors, such as Adams ${ }^{[21]}$, evaluated the STS registry from 1996 to 2005, and found that, in a group of 89 patients with 28 patients with EF $<25 \%$ and 61 patients with EF $>25 \%$, the hospital mortality rate was 3.4 (without significance), but with total survival in five years of $82 \%$, being $69.6 \%$ in the EF group $<25 \%$ and $88.3 \%$ in the $E F$ group $>25 \%$, with significance. However, the search for a better evaluation was performed through a multicenter, randomized study, the STICH Trial[12-14], which investigated two hypotheses. The first one compared patients in clinical treatment against clinical treatment and MR, and in the second hypothesis, patients were compared in clinical treatment and MR against clinical treatment, MR, and SVR. The results obtained in this study did not demonstrate advantage in the treatment group of ventricular reconstruction, but methodological failures have been described and defined; according to Athanasuleas ${ }^{[22]}$, presence of viability test was only observed in $27.6 \%$ of the patients with ventricular reduction in 19\%, while, in other studies, it was reported $>30 \%$ of ventricular reduction, as well as a reduction in the volume of the inadequate left ventricle in $44 \%$ of the patients and in $18.5 \%$ of patients with SVR without left ventricular volume reduction. Therefore, the European Society of Cardiology/European Association for Cardiothoracic Surgery (ESC/EACTS) contradicts the conclusion of the STICH Trial and recommends that MR surgery and SVR should be considered in patients with left ventricular end-systolic volume index (LVESVI) $>60 \mathrm{ml} / \mathrm{m}^{2}$ and aneurysm in the territory of the anterior interventricular artery in centers with high level of experience.

After the outcome of the STICH Trial's hypothesis 2, research on the treatment of SVR was intensified, and authors like Isomura ${ }^{[23]}$ demonstrated that this procedure is more effective when $33 \%$ of ventricular reduction is obtained and LVESVI < $90 \mathrm{ml} / \mathrm{m}^{2}$, as well as there is no long-term benefit when SVR induces a left ventricular volume reduction $<15 \%$ and leaves residual LVESVI $>90 \mathrm{ml} / \mathrm{m}^{2}$. Calafiore ${ }^{[24]}$, in a group of patients with ischemic mitral insufficiency in $90.3 \%$ of them and NYHA III-IV in $77.9 \%$, with mean EF of $26 \%$, and akinetic areas at the site of ventricular scar in $86.7 \%$, demonstrated no deaths from any cause and NYHA III-IV in 61\%.

The results obtained in this study showed a general mortality rate of $14.7 \%$, with a hospital rate of $8.82 \%$ and late death of $5.88 \%$, as well as total survival rate in five years of $85.3 \%$. Of the analyzed variables, the change in FC and EF, although not statistically significant, showed a not insignificant clinical improvement. We believe that the result was a consequence of the limited number of patients.

Based on these data, we maintain the opinion in favor of the indication of SVR for patients with ventricular dysfunction and candidates for HTx. This opinion is based on two pillars: the first being the impossibility of having enough heart donors in Brazil and in the whole world, perpetuating a restricted demand, which in Brazil, in the year 2016, left an estimated deficit of 1,279 transplants. Secondly and not least, the Brazilian survival result of $H \mathrm{TX}^{[15]}$, a treatment considered gold standard for patients with end-stage HF, presented values of $73 \%$ in the first year and $63 \%$ in five years. Survival data from the International Society of Heart and Lung Transplantation (ISHLT) ${ }^{[25]}$ for HTx were $81.97 \%$ in the first year and $69.64 \%$ in five years.

\section{Limitations}

We believe that the limitation of this study is related to the small number of patients, as well as to the study design, because it is retrospective and single-center.

\section{CONCLUSION}

The surgical treatment of left ventricular reconstruction in patients who are candidates for HTx is effective, efficient, and safe, providing an adequate survival rate.

\section{Ethical Considerations}

This research respected the principles of the Declaration of Helsinki, good clinical practice, and the confidentiality of data obtained.

This research was presented in order to earn a specialist degree in Cardiovascular Surgery from the Brazilian Cardiovascular Surgery Society (SBCCV).

\section{No financial support. \\ No conflict of interest.}




\section{Authors' roles \& responsibilities}

CAMC Substantial contributions to the conception or design of the work; or the acquisition, analysis, or interpretation of data for the work; drafting the work or revising it critically for important intellectual content; agreement to be accountable for all aspects of the work in ensuring that questions related to the accuracy or integrity of any part of the work are appropriately investigated and resolved; final approval of the version to be published

PXO Drafting the work or revising it critically for important intellectual content; final approval of the version to be published

AFSA Drafting the work or revising it critically for important intellectual content; final approval of the version to be published

MAF Drafting the work or revising it critically for important intellectual content; final approval of the version to be published

JMRN Drafting the work or revising it critically for important intellectual content; final approval of the version to be published

PC Drafting the work or revising it critically for important intellectual content; final approval of the version to be published

\section{REFERENCES}

1. Datasus: Departamento de Informática do SUS. Mortalidade por infarto agudo do miocárdio no Brasil. Brasília: Ministério da Saúde; 2014.

2. Athanasuleas CL, Buckberg GD, Stanley AW, SilerW, DorV, DiDonato M, et al. Surgical ventricular restoration: the RESTORE Group experience. Heart Fail Rev. 2004;9(4):287-97. doi:10.1007/s10741-005-6805-4.

3. Janaswamy P, Walters TE, Nazer B, Lee RJ. Current treatment strategies for heart failure: role of device therapy and LV reconstruction. Curr Treat Options Cardiovasc Med. 2016;18(9):57. doi:10.1007/s1 1936-016-0479-1.

4. Di Donato M, Castelvecchio S, Menicanti L. Surgical treatment of ischemic heart failure: the Dor procedure. Circ J. 2009;73 Suppl A:A1-5.

5. Cooley DA, Collins HA, Morris GC Jr, Chapman DW. Ventricular aneurysm after myocardial infarction; surgical excision with use of temporary cardiopulmonary bypass. J Am Med Assoc. 1958;167(5):557-60.

6. Jatene AD. Left ventricular aneurysmectomy: resection or reconstruction. J Thorac Cardiovasc Surg. 1985;89(3):321-31.

7. Dor V, Saab M, Coste P, Kornaszewska M, Montiglio F. Left ventricular aneurysm: a new surgical approach. Thorac Cardiovasc Surg. 1989;37(1):119. doi:10.1055/s-2007-1013899.

8. Cooley DA. Ventricular endoaneurysmorrhaphy: a simplified repair for extensive postinfarction aneurysm. J Card Surg. 1989;4(3):200-5. doi:10.1111/j.1540-8191.1989.tb00282.x.

9. Mickleborough LL, Maruyama H, Liu P, Mohamed S. Results of left ventricular aneurysmectomy with a tailored scar excision and primary closure technique. J Thorac Cardiovasc Surg. 1994;107(3):690-8.

10. Dinkhuysen JJ, Santos M, Sousa LCB, Chaccur P, Abdulmassih Neto C, Arnoni AS PI, et al. [Early and late results of surgical correction of left ventricle aneurysms]. Rev Bras Cir Cardiovasc. 1993;8(3):225-36. doi:10.1590/S0102-76381993000300007. Portuguese.
11. Athanasuleas CL, Stanley AW, Buckberg GD, Dor V, Di Donato M, Siler $W$, et al. Surgical anterior ventricular endocardial restoration (SAVER) for dilated ischemic cardiomyopathy. Semin Thorac Cardiovasc Surg. 2001;13(4):448-58. doi:10.1016/S0735-1097(01)01119-6.

12. Velazquez EJ, Lee KL, Deja MA, Jain A, Sopko G, Marchenko A, et al. Coronaryartery bypass surgery in patients with left ventricular dysfunction. N Engl J Med. 2011;364(17):1607-16. doi:10.1056/NEJMoa1100356.

13. Petrie MC, Jhund PS, She L, Adlbrecht C, Doenst T, Panza JA, et al. Tenyear outcomes after coronary artery bypass grafting according to age in patients with heart failure and left ventricular systolic dysfunction: an analysis of the extended follow-up of the STICH Trial (Surgical Treatment for Ischemic Heart Failure). Circulation. 2016;134(18):131424. doi:10.1161/CIRCULATIONAHA.116.024800.

14. Jones RH, Velazquez EJ, Michler RE, Sopko G, Oh JK, O'Connor CM, et al. Coronary bypass surgery with or without surgical ventricular reconstruction coronary bypass surgery with or without surgical ventricular reconstruction. N Engl J Med. 2009;360(17):1705-17. doi:10.1056/NEJMoa0900559.

15. 1Registro Brasileiro de Transplante: dados númericos da doaçao de órgaos e transplantes realizados por estado e instituiçao no periodo de janeiro a setembro 2016 [Internet]. São Paulo: ABTO: Associação Brasileira de Transplante de Orgaos; 2016 [cited 2019 May 10]. 22 p. Available from: http://www.abto.org.br/abtov03/Upload/file/RBT/2016/RBT20163t-let.pdf

16. Adachi Y, Sakakura K, Wada H, Funayama H, Umemoto T, Fujita H, et al. Determinants of left ventricular systolic function improvement following coronary artery revascularization in heart failure patients with reduced ejection fraction (HFrEF). Int Heart J. 2016;57(5):565-72. doi:10.1536/ihj.16-087.

17. Monaco M, Stassano P, Di Tommaso L, Pepino P, lannelli G, Spampinato N. Surgery for left ventricular aneurysm: is there still any role for simple linear repair? J Card Surg. 2009;24(2):156-61. doi:10.1111/j.1540-8191.2009.00825.X.

18. Marchenko AV, Cherniavsky AM, Volokitina TL, Alsov SA, Karaskov AM. Left ventricular dimension and shape after postinfarction aneurysm repair. Eur J Cardiothorac Surg. 2005;27(3):475-80; discussion 80. doi:10.1016/j. ejcts.2004.12.025.

19. D'Mello M, Kurudamannil AA, Reddy DJ, Raju PS. Postmyocardial infarction left ventricular dysfunction - assessment and follow up of patients undergoing surgical ventricular restoration by the endoventricular patchplasty. Indian Heart J. 2013;65(1):17-23. doi:10.1016/j.ihj.2012.12.023.

20. Tekümit H, Polat A, Uyar I, Uzun K, Tataroğlu C, Cenal AR, et al. Left ventricular aneurysm using the Dor technique: mid-term results. J Card Surg. 2010;25(2):147-52. doi:10.1111/j.1540-8191.2009.00971.x.

21. Adams JD, Fedoruk LM, Tache-Leon CA, Peeler BB, Kern JA, Tribble CG, et al. Does preoperative ejection fraction predict operative mortality with left ventricular restoration? Ann Thorac Surg. 2006;82(5):1715-9; discussion 1719-20. doi:10.1016/j.athoracsur.2006.05.035.

22. Athanasuleas C, Buckberg G, Conte J.The STICH trial data: Keep it simple. J Thorac Cardiovasc Surg. 2015;149(6):1682-3. doi:10.1016/j.jtcvs.2015.01.074.

23. Isomura T, Hoshino J, Fukada Y, Kitamura A, Katahira S, Kondo T, et al. Volume reduction rate by surgical ventricular restoration determines late outcome in ischaemic cardiomyopathy. Eur J Heart Fail. 2011;13(4):423-31. doi:10.1093/eurjhf/hfa227.

24. Calafiore AM, laco AL, Kheirallah H, Sheikh AA, Al Sayed H, El Rasheed M, et al. Outcome of left ventricular surgical remodelling after the STICH trial. Eur J Cardiothorac Surg. 2016;50(4):693-701. doi:10.1093/ejcts/ezw103.

25. Lund LH, Edwards LB, Dipchand Al, Goldfarb S, Kucheryavaya AY, Levvey $B J$, et al. The registry of the international society for heart and lung transplantation: thirty-third adult heart transplantation report-2016; Focus theme: primary diagnostic indications for transplant. J Heart Lung Transplant. 2016;35(10):1158-69. doi:10.1016/j.healun.2016.08.017. 